УДК 39(470.51)(045)

\title{
И.А. Косарева
}

\section{УДМУРТСКО-ТЮРКСКОЕ ЭТНОКУЛЬТУРНОЕ ВЗАИМОДЕЙСТВИЕ И БЕСЕРМЯНСКАЯ ПРОБЛЕМАТИКА В СВЕТЕ ПОЛЕВЫХ ИССЛЕДОВАНИЙ ПОСЛЕДНЕГО ВРЕМЕНИ}

В статье рассматриваются явления традиционной материальной культуры, отразившие этнокультурное взаимодействие удмуртского народа с тюрками - булгарами, казанскими тарами и башкирами. Разные этнографические и этнические группы удмуртского народа обнаруживают имевший место в прошлом устойчивый консерватизм по отношению к такому важному знаковому предмету, каковым был женский головной убор на берестяной основе. Аналогичное явление наблюдалось у коми, марийцев и мордвы. Тесное взаимодействие с тюрками привело к утрате бесермянами и частью удмуртов головного убора на берестяной основе и замене его матерчатым чепцом с разомкнутым верхом. Нательные рубахи в традициях наиболее изолированных этнографических и этнических подразделений удмуртов сохранили старейший туникообразный покрой со сдвинутым вправо нагрудным разрезом, известный также у коми и луговых марийцев. В результате этнокультурного взаимодействия с тюрками в традициях бесермянского субэтноса и ряда этнографических групп удмуртов появилась рубаха туникообразного покроя с центральным нагрудным разрезом и нижний нагрудник кыкрак. Тюркское влияние проявилось появлением у части южных удмуртов и бесермян штанов с широким шагом, сменивших штаны с узким шагом. Наборы традиционных украшений из серебряных монет бесермян и многих этнографических подразделений удмуртов включали перевязь, заимствованную от разных тюркских этносов, что выразилось в названиях этого предмета. Процесс, приведший к формированию бесермянского субэтноса, отразился в возникновении форм традиционного костюма, близких к традициям тюркских народов. Аналогичной направленности процессы имели место и у различных этнографических и этнических подразделений удмуртского народа. Они также отражены в формах традиционной одежды.

Ключевые слова: удмуртско-тюркское взаимодействие, бесермяне, удмурты Закамья, верхнеижско-шарканские удмурты, традиционный костюм.

DOI: $10.35634 / 2412-9534-2021-31-4-797-804$

Этнокультурное взаимодействие уральских и тюркских народов в Урало-Поволжском регионе на протяжении многих столетий имело значительный ареал и носило перманентный характер. Нас интересуют в данном случае те его аспекты, которые так или иначе связаны с бесермянским субэтносом и отражены в материальной культуре - в традиционной одежде, головных уборах, украшениях, традиционной вышивке счётными швами бесермян и различных этнографических подразделений удмуртского народа.

Как известно, традиционные удмуртские женские головные уборы на берестяной основе (айшон) у собственно-южных удмуртов сохранялись в повседневном быту до конца XIX в.; у завятских и бавлинских удмуртов (ашъян) - до 1930-х гг. (времени коллективизации). Северные удмурты использовали подобный головной убор (ашкон), по крайней мере, в первой четверти XVIII в. [19, с. 86]. Аналогами удмуртскому головному убору на берестяной основе у родственных этносов являются юртыр коми, шурка марийцев, панго мордвы.

Женский головной убор на берестяной основе - обрядово значимый статусный предмет - отсутствовал в костюме бесермян. Вместо него бытовал матерчатый чепец с разомкнутым верхом каш$n y$, по своей конструкции и названию близкий женскому головному убору чувашей.

Языковедами и историками были высказаны две противоположные точки зрения по вопросу о происхождении бесермян: 1) бесермяне в основе своей - удмурты, испытавшие сильное тюркское воздействие; 2) бесермяне - обудмуртившиеся тюрки.

Совершенно очевидно, что противопоставление двух этих точек зрения бессмысленно. Бесспорно участие в формировании бесермян и удмуртского, и тюркского (булгаро-чувашского) компонентов. Для нас существенно понять, при каких конкретно обстоятельствах и как могло сформироваться у некой группы населения, давшей начало бесермянскому субэтносу такое сочетание черт культуры, как удмуртский язык и неудмуртские, близкие чувашским, формы одежды.

По всей видимости, в районе активных межэтнических контактов (на юго-западной периферии удмуртской этнической территории) имело место активное этнокультурное взаимодействие удмуртов 
и булгар. Оно отразилось в традиционном костюме формировавшегося бесермянского субэтнса. Хотя женская одежда как элемент материальной культуры в традиционном обществе не была столь активно подвержена влияниям извне, как это характерно для индустриального общества, и само понятие «моды» в современном понимании тогда не существовало, тем не менее одежда отразила культурное влияние политически доминировавшего булгарского этноса.

Наверняка в этом взаимодействии удмуртов и булгар значительную роль играли смешанные браки, при которых тюркские девушки, являвшиеся носителями традиции изготовления булгарочувашской одежды, выходили замуж в удмуртские деревни. Выходя за удмуртов замуж, они оказывались в удмуртской языковой среде. Повседневные хозяйственно-бытовые контакты диктовали освоение инородками удмуртского языка. Потомки этих смешанных браков с рождения находились в удмуртской среде и усваивали в качестве основного языка удмуртский. (Изначально могло иметь место двуязычие). Такое смешение этносов должно было осуществляться длительное время, на протяжении нескольких поколений, а может происходить несколькими волнами.

Мы многого не знаем об эпохе бесермянского этногенеза, но иная схема развития событий исключена, потому что носителем языка является весь этнос, а преемственность в традициях изготовления одежды осуществляется в деятельности его женской половины. Эту версию подтверждают материалы недавних генетических исследований, проведённых у бесермян. Результаты исследования митохондриальной ДНК, генетические маркеры которой передаются по материнской линии от матери ко всем детям, указывают на то, что по женской линии бесермяне генетически сближаются с тюркоязычными народами Южной Сибири. [9, с. 1337-1344]. В то же время данные исследования гаплогрупп Y хромосомы, генетические маркеры которой передаются исключительно по отцовской линии (от отца к сыновьям), свидетельствуют о преобладании финно-угорского компонента в формировании бесермян по мужской линии [22, с. 120-127].

Именно формирование бесермянского субэтноса в процессе взаимодействия удмуртов с тюрками привёло к замене очень важного для носителей исконных удмуртских традиций женского берестяного головного убора матерчатым чепцом кашny с разомкнутым верхом, унаследованным бесермянами от булгар и конструктивно очень близким чувашскому хушиу.

Однако удмуртско-тюркское взаимодействие вылилось в формирование не только бесермян, но и этнографических групп удмуртов, утративших подобно бесермянам головной убор на берестяной основе, заменивших его на матерчатый чепец с разомкнутым верхом. Это - удмурты Закамья, населяющие северо-западный Башкортостан, и верхнеижско-шарканские удмурты, проживающие в Шарканском и Якшур-Бодьинском районах.

В традиции удмуртов Закамья мы обнаруживаем женский головной матерчатый чепец с разомкнутым верхом - манлай. Его покрой и название указывают на усвоение удмуртскими переселенцами в северо-западном Башкортостане башкирских традиций. Другим наглядным результатом влияния тюркских традиций на удмуртов Закамья стало заимствование закладной техники узорного ткачества, позволяющей создавать безворсовые ковры со специфическими узорами, а также изготовление полосатых тканых изделий для декорирования интерьера.

У верхнеижско-шарканских удмуртов мы встречаем женский головной матерчатый чепец с разомкнутым верхом - nодурга. По данным Г. Е. Верещагина, хорошо знавшего этнографический материал, подурга сзади спускалась ниже поясницы [7, с. 26]. То есть подурга имела лопасть и была подобна старинным головным уборам татар, башкир и чуваш. (До наших дней сохранились образцы без лопасти, с вышитым на затылке небольшим лоскутом).

В оформлении традиционной одежды (рубах, фартуков, головных полотенец) верхнеижскошарканские удмурты, так же как и удмурты Закамья, активно применяли закладную технику ткачества. Её же применяли при создании вещей для декорирования интерьера. У верхнеижско-шарканских удмуртов сформировался интересный тип предмета - валес шобрет 'постели покрывало' с массивным выразительным закладным узором в боковой части. Этот узор эффектно декорировал боковую вертикальную плоскость застланной постели. Особое пристрастие верхнеижско-шарканские удмурты имели и к полосатым тканым покрывалам, которыми драпировали интерьер. Их ткали с простыми цветными полосами, играя цветовыми сочетаниями, а также наделяли цветовыми растяжками в полосах или яркими сочными пунктирными строчками [14, с. 91-96].

Характерные для закамских и верхнеижско-шарканских удмуртов матерчатые чепцы с разомкнутым верхом манлай и подурга, широкое использование закладной техники, изготовление полосатых 
Удмуртско-тюркское этнокультурное взаимодействие и бесермянская проблематика...

тканей - всё это свидетельствует об интенсивном влиянии тюркских (башкирских и татарских) традиций на оба этнографических подразделения удмуртского народа, населяющих юго-восточную и восточную периферию удмуртской этнической территории. Однако эти контакты имели иной качественный характер. Они не привели к появлению новых субэтносов, не сопровождались выработкой новых эндоэтнонимов. Закамские и верхнеижско-шарканские удмурты как были, так и остались по самосознанию и самоназванию удмуртами и в полном объёме сохранили свои исконные языческие верования.

В то же время в этнической истории удмуртского народа имели место массовые смешанные браки с татарами. В их основе лежало полное принятие удмуртами ислама, и в результате всё это приводило к массовому отатариванию, массовой ассимиляции, сокращению удмуртской этнической территории. Об этом много писали деятели церкви в XIX в. и исследователи советского времени $[2$, c. $4-36 ; 5$, c. $46-47 ; 10$, c. $138-142]$.

Имевшие место в прошлом процессы межэтнического взаимодействия в Урало-Поволжском регионе слабо отражены в письменных источниках. При этом очень важную информацию можно получить при анализе материалов по традиционной одежде.

Поскольку именно нательная одежда наименее подвержена конструктивным изменениям и сохраняет формы, возникшие очень давно [8, с. 4-5], важно обратить внимание на покрой нательной одежды. У наиболее изолированных от внешних влияний групп удмуртского народа до последнего периода полноценного бытования традиционного костюма сохранились рубахи прямого туникообразного покроя со сдвинутым вправо нагрудным разрезом. Это косинские удмурты, проживающие в бассейне р. Косы (левый приток р. Чепцы), изготавливавшие свои рубахи только из белого домотканого холста. Это так наз. унинские калмезы, деревни которых расположены в Унинском районе Кировкой области в верховьях небольших рек, относящихся к бассейну р. Кильмезь. (Унинские калмзы и калмезы, проживающие в основной части бассейна р. Кильмезь - разные этнографические подразделения удмуртского народа $[13$, с. $135-141])$. Они сохраняли этот покрой и в белых холщёвых одеждах, и в рубахах из пестряди, и при использовании пестряди вкупе с фабричными тканями. Это слободские удмурты, изменившие крой нагрудного разреза женских рубах, но не посмевшие проделать то же самое с девичьими рубахами, в оформлении которых была обязательна нашивка-оберег гадь котыртем 'грудь ограждена', располагаемая обязательно слева от разреза. Подобный покрой сохранился в мужских рубахах коми [4, с. 242] и у части луговых марийцев [18, с. 15-22].

Присутствие этого покроя в традициях родственных этносов наводит на мысль о том, что он был характерен уже для населения предананьинского этнокультурного массива XI-VIII вв. до н. э., в среде которого исследователи усматривают прапермян и прамарийцев [11, с. 34].

Появление у марийцев рубах с центральным нагрудным разрезом Т. Л. Молотова объясняет чувашским влиянием [18, с. 20-21].

Удмуртские женские рубахи конца XIX - начала XX в. из пестряди с центральным нагрудным разрезом без планки имели вокруг этого разреза декоративное оформление подковообразной формы, выполненное из нашитых тканей, позумента и кружев. Такие рубахи были распространены среди собственно-южных удмуртов и удмуртов Закамья. Их появление в удмуртской традиции - результат тюркского (татарского и башкирского) влияния. В татарской традиции был подковообразный матерчатый нагрудник изу, происхождение которого специалисты также связывают с оформлением нагрудного разреза рубахи [21, с. 139].

Интересно, что у завятских удмуртов бытовал особый праздничный нагрудник тоже подковообразной формы, декорированный позументом уко муресазь 'блестящий нагрудник'. Он также появился в результате влияния татарских традиций.

У собственно-южных и закамских удмуртов ношение рубахи с большим (до 25 cм) нагрудным разрезом без планки, настежь раскрывающим грудь, предполагало наличие надеваемого под рубаху нагрудника. И такой нагрудник в удмуртской традиции был. Его образцы сохранились. Он представляет собой кусок холста с загнутыми и подшитыми верхними углами, скромно декорированный ткаными полосками, тамбурной вышивкой или аппликацией. Его фиксировали на теле при помощи перекрещенных за спиной лямок. Подобные нагрудники были в традиции казанских татар и башкир. У собственно-южных удмуртов название этого нагрудника кыкрак явно имеет тюркское происхождение. Его аналоги известны в татарской традиции под названием кукракча, а в башкирской - кyкракся. Терминология, связанная с этим предметом, не оставляет сомнений в его появлениив в удмуртской традиции в результате тюркского культурного влияия [3, с. 46]. 
Если бы у нас была возможность изучить на всей удмуртской этнической территории вещи, типичные для более раннего времени (хотя бы XVII-XVIII вв.), у нас была бы интересная информация об историческом пути, пройденном разными этнографическими подразделениями удмуртского народа. Однако модернизация традиционной одежды, в частности, появление рубах, близких по покрою к городскому платью, стёрли многие специфические особенности локальных вариантов удмуртского традиционного костюма. Тем не менее некоторые находки дают пищу для размышлений и подводят к некоторым выводам.

Тюркское воздействие привело к появлению рубах с центральным нагрудным разрезом и у калмезов, населяющих основную часть бассейна р. Кильмезь. Такой покрой обнаружен благодаря сохранившимся нагрудным вышитым фрагментам давно вышедших из употребления и полностью утраченных белых холщёвых рубахах [13, с. 135-141].

Далее, как хорошо известно, бесермянская женская белая холщёвая рубаха имеет центральный нагрудный разрез (такую рубаху обязательно носили с нижним белым холщёвым нагрудником). Перпендикулярно к нагрудному разрезу нашиты сплетённые из толстых красных льняных нитей рельефные полоски изма, в промежутках между которыми вышит повторяющийся мотив, чаще всего геометризованные изображения дерева. Термин изма происходит из тюркских языков. Башкиры обозначали словом изе нашивки из лент, полосок цветной ткани вокруг нагрудного разреза старинных женских рубах [24, с. 153]. У казанских татар изу - нагрудное украшение [6. с. 70]. Нижняя часть нагрудного разреза бесермянской рубахи имеет мысовидное завершение, подчёркнутое нашивками из красной фабричной ткани.

Поскольку этническая история бесермянского субэтноса до переселения в бассейн р. Чепцы была связана с юго-западом удмуртской этнической территории [23, с. 313], интересны материалы, полученные на юго-западе Удмуртии.

В ходе полевых исследований у этнографической группы, известной в литературе под названием «собственно-южные удмурты», удалось выявить 6 этнографических подразделений, 6 подгрупп, обладающих специфическими особенностями традиционной культуры. Среди них водзимоньинские удмурты. Ареал этой подгруппы находится в юго-западной части удмуртской этнической территории, на западе Вавожского района, в деревнях, расположенных вокруг с. Водзимонье [15, с. 17-21].

До появления в конце XIX - начале XX в. одежды из пестряди и фабричных тканей, имеющей модернизированный покрой, водзимоньинские удмурты носили белые холщёвые рубахи с центральным нагрудным разрезом. Декоративное оформление нагрудного разреза их рубах было близко тому, как оформляли свои рубахи бесермяне: место плетёных нашивок изма занимают полосы рельефной вышивки, между которыми ритмично повторяются простёганные чёрной нитью швом «роспись» фигуры. В ряде образцов они близки своими очертаниями схемам бесермянскго мотива нагрудной вышивки, содержащей древовидное изображение, выполненное в упрощённом виде. В одном из сохранившихся фрагментов нагрудной части рубахи между рельефными полосками простёганы очертания S-образных фигур. Этот мотив также характерен и для бесермянской традиционной вышивки. Нижняя часть нагрудного разреза водзимоньинских рубах имеет мысовидное завершение, не столь декоративно выделенное, как у бесермян, но ясно обозначенное.

Удмуртско-тюркское взаимодействие, уходящее корнями в булгарскую эпоху, привело к изменению покроя нательной рубахи, к появлению рубах с центральным нагрудным разрезом и возникновению специфического декоративного оформления такого разреза, демонстрирующего черты сходства у бесермян и удмуртов водзимоньинской подгруппы.

В контексте удмуртско-тюркского взаимодействия интересно было бы проанализировать распространение разных типов покроя штанов - важного обязательного элемента удмуртской женской нательной одежды. Полевыми исследованиями установлено, что у разных групп удмуртов был распространён единый конструктивный тип штанов «с узким шагом» [12, с. 72; 17, с. 57, илл. 114-116]. В ходе полевых исследований он был обнаружен у северных удмуртов ватка, собственно-южных удмуртов и калмезов.

В то же время на юге удмуртской этнической территории у части собственно-южных удмуртов в результате активного взаимодействия с тюрками получили распространение штаны «с широким шагом», для конструкции которых характерно наличие широкого полотнища, вшитого между штанинами $[17$, с. 87,112 , илл. 164-168]. Такой покрой, как известно, был характерен для тюркских народов. Однако репрезентативного материала, позволяющего отыскать в пределах удмуртской этнической территории границу между ареалами обоих типов, собрать не удалось. Штаны, не находившиеся 
Удмуртско-тюркское этнокультурное взаимодействие и бесермянская проблематика...

801 СЕРИЯ ИСТОРИЯ И ФИЛОЛОГИЯ

2021. Т. 31, вып. 4

в употреблении, сохранились до наших времён в единичных случаях. Именно они и доступны этнографическому изучению. Ношеные штаны, даже если они уцелели, обычно прячут. Для нас важно, что покрой «с широким шагом» частью южных удмуртов был усвоен. Этот покрой был характерен и для бесермянской традиции [3, с. 102], что обусловлено историей формирования данного субэтноса.

При значительной модернизации форм традиционной одежды разных этнографических групп удмуртского народа большой интерес представляют украшения. У всех исторически сложившихся групп удмуртского этноса в конце XIX - начале XX в. бытовали особые наборы украшений, отличавшиеся по составу предметов, их конструкции и терминологии. Явным следом тюркского влияния на удмуртов была перевязь. Её не было только у наиболее изолированных от внешнего мира подразделений удмуртов.

Перевязь под разными названиями бытовала почти у всех этнографических подразделений удмуртов. Её присутствие обусловлено тесными культурно-историческими контактами с носителями ислама. Последние использовали перевязь в качестве оберега, к которому прикрепляли сумочку с миниатюрным Кораном или текстом молитвы [16, с. 83-87]. Была перевязь и в праздничном женском костюме бесермян.

Интересно, что у бесермян, завятских удмуртов, как кукморских, так и шошминскиих, и у северных удмуртов ватка перевязь имела название камали [3, с. 103; 12, с. 149; 20, с. 61-62]. Данный термин языковеды Р. Ш. Насибуллин и С. А. Максимов связывают с булгарским словом, обозначающим 'серебро' (личное сообщение). Совершенно очевидно, что это название появилось в результате контактов с булгарами. Все упомянутые в связи с перевязью камали подразделения удмуртского народа исторически связанны с юго-западной периферией удмуртской этнической территории. Они испытали в прошлом заметное влияние культуры волжских булгар и, в частности, заимствовали у них перевязь с булгарским названием.

В то же время несколько подгрупп собственно-южных удмуртов (алнашско-киясовская, граховско-южнокизнерская, можгинско-малопургинская) и часть калмезов, проживающих в нижнем течении p. Кильмезь, имели в наборах своих традиционных украшений перевязь под названием бутьмар. Данное название заимствовано из татарского языка (путемар - перевязь с сумочкой для хранения миниатюрного Корана или записи текста молитвы) [1, с. 164]. Очевидно, что в данном случае и перевязь, и термин, её обозначающий, были усвоены удмуртами благодаря контактам с казанскими татарами.

А у нескольких этнографических подразделений удмуртов перевязь также присутствовала в наборе традиционных украшений, но она была известна под удмуртским названием: сюмыс бырттон (калмезы верхнего течения р. Кильмезь), сюмыс бырттос (среднеижская левобережная подгруппа собственно-южных удмуртов), силь сюмыс (удмурты Закамья). Эти названия образованы от удмуртских слов сюмыс 'сыромятная кожа', бырттыны 'продеть, нанизать', силь 'загривок'. Использование удмуртских лексем для обозначения этого предмета свидетельствует об ослаблении тюркского языкового влияния, но отнюдь не об отсутствии культурного воздействия. Перевязь как специфическое украшение и одновременно оберег была этими подразделениями усвоена, и этот факт свидетельствует об интенсивных контактах с тюрками.

Традиционное удмуртское узорное ткачество, имеющее давние истоки, достигшее своего апогея с появлением анилиновых красителей, развивалось также под значительным влиянием тюркских традиций. Это обстоятельство особенно значимо для собственно-южных, верхнеижско-шарканских и закамских удмуртов. Такие явления как пестрядь (клетчатая ткань для изготовления одежды), закладная техника, техника ложного ажурного ткачества и многообразные орнаментированные вещи, выполненные в выборной и переборной технике, их яркое многоцветие с необычайно подвижным асимметричным решением цветовой композиции, свидетельствует о творческих контактах с носителями тюркских традиций и переработке этих художественных впечатлений.

Подводя итоги, констатируем, что многовековое общение удмуртов с тюркскими этносами имело различные результаты:

1) полную ассимиляцию части удмуртов казанскими татарами через принятие ислама;

2) формирование бесермянского субэтноса со своей специфической культурой, удмуртским языком и новым эндоэтнонимом;

3) обогащение традиционного удмуртского народного искусства и традиционной одежды в результате общения с тюрками, творческая переработка этих художественных впечатлений при сохранении этнического самосознания и исконного эндоэтнонима. 
Для нас интересно и важно рассматривать формирование бесермянского субэтноса и его традиционной культуры в общем контексте удмуртско-тюркского взаимодействия. Последнее происходило в разные исторические периоды и было связано с разными группами тюрок. Оно отражено в удмуртской материальной культуре. Продолжительное этнокультурное общение разных исторически сложившихся групп удмуртского народа и тюркских этносов определило специфику традиционной материальной культуры и бесермян, и разных этнографических подразделений удмуртского народа.

\section{СПИСОК ИСТОЧНИКОВ И ЛИТЕРАТУРЫ}

1. Ахметьянов Р. Г. Краткий историко-этимологический словарь татарского языка. Казань: Тат. книжн. изд-во, 2001. 272 c.

2. Багин C. Об отпадении в магометанство крещёных инородцев Казанской епархии и о причинах этого печального явления. Казань: Центральная типография, 1910. 38 с.

3. Белииер В. Н. Народная одежда удмуртов (материалы к этногенезу) // ТИЭ. Нов. сер. / отв. ред. Н. Н. Чебоксаров. М.: Изд-во АН СССР, 1951. 142 с.

4. Белицер В. Н. Очерки по этнографии коми // ТИЭ. Нов. сер. Т. 45 / отв. ред. Н. Н. Чебоксаров. М.: Изд-во АН CCCP, 1958. $322 \mathrm{c}$.

5. Бобровников Н. А. Инородческое население Казанской губернии. Вып. І. Казань: [б. и.], 1899. 68 с.

6. Валеев Ф. Х. Народное декоративное искусство Татарстана. Казань: Тат. книжн. изд-во, 1984. 172 с.

7. Верещагин Г. Е. Вотяки Сосновского края. // Собр. соч.: в 6 т. Т. І. Серия «Памятники культуры». Ижевск: УИИЯЛ УРО РАН, 1995. $215 \mathrm{c}$

8. Гаген-Торн Н. И. Женская одежда народов Поволжья (Материалы к этногенезу). Чебоксары: Чуваш. книжн. изд-во, 1960. 228 с.

9. Грошева А. Н., Шнейдер Ю. В., Морозова И. Ю., Жукова О. В., Рычков С. Ю. Генетическое разнообразие бесермян по данным о полиморфизме митохондриальной ДНК // Генетика. 2013. № 11. С. 1337-1344.

10. Кельмаков B. K. К истории удмуртов Правобережья р. Вятки // Материалы по этногенезу удмуртов. Ижевск: НИИ при СМ УАССР, 1982. С. 138-142.

11. Козлова К. И. Очерки этнической истории марийского народа. М.: Изд-во МГУ, 1978. 345 с.

12. Косарева И. А. Традиционная женская одежда периферийных групп удмуртов. Ижевск: УИИЯЛ УрО РАН, 2000. $226 \mathrm{c}$.

13. Косарева И. А. Калмез - этнографическая группа удмуртов. (Особенности традиционной культуры и локализация) // Вестн. Удм. ун-та. Сер.: История и филология. 2011. № 3. С. 135-141.

14. Косарева И. А. Верхнеижско-шарканская этнографическая группа удмуртов в свете проблемы удмуртскотюркского взаимодействия // Вестн. Удм. ун-та. Сер. : История и филология. 2012. № 1. С. 91-96.

15. Косарева И. А. Водзимоньинская подгруппа собственно-южных удмуртов // Вестн. Челяб. Ун-та. 2015. № 65. C. 17-21.

16. Косарева И. А. Наборы украшений этнографических подразделений удмуртов. (Сравнительный анализ.) // Вестн. Удм. ун-та. Сер.: История и филология. 2017. № 1. С. 83-87.

17. Косарева И. А. Этнографические группы удмуртского народа (опыт выделения) // ИОАИЭ при Казан. ун-те. 2017. Т. 37. Ч. 2. 195 с.; Ч. 3. 187 c.

18. Молотова Т. Л. Марийский народный костюм. Йошкар-Ола: Марийское книжн. изд-во, 1992. 109 с.

19. Напольских В. В. Удмуртские материалы Д. Г. Мессершмидта. Ижевск: Удмуртия, 2001. 222 с.

20. Первухин Н. Г. Эскизы преданий и быта инородцев Глазовского уезда. Эскиз V. Вятка: [б. и.], 1890.68 с.

21. Суслова С. В. Татарский костюм. Историко-этнологическое исследование. Казань: Тат. книжн. изд-во, 2018. $238 \mathrm{c}$.

22. Трофимова Н. В., Литвинов С. С., Хусаинова Р. И. и др. Генетическая характеристика популяций ВолгоУральского региона по данным об изменчивости Ү-хромосомы // Генетика. 2015. Т. 51, № 1. С. $120-127$.

23. Трефилов Г. Н. Бесермяне по письменным источникам // ВФУЯ. Вып. IV. Ижевск: [б. и.], 1967. С. $310-318$.

24. Шитова С. Н. Народная одежда башкир // Археология и этнография Башкирии. Т. 3. Уфа: [б. и.], 1968. C. $125-227$.

Косарева Ирина Алексеевна, кандидат исторических наук, доцент кафедры изобразительного искусства и художественной культуры ФГБОУ ВО «Удмуртский государственный университет» 426034, Россия, г. Ижевск, ул. Университетская, 1 (корп. 6) E-mail: kosar_irina@mail.ru 


\title{
I.A. Kosareva \\ UDMURT-TURKIC ETHNO-CULTURAL INTERACTION AND THE BESERMYAN PROBLEM IN THE LIGHT OF THE LATEST FIELD RESEARCH
}

\author{
DOI: 10.35634/2412-9534-2021-31-4-797-804
}

The article is devoted to the phenomena of traditional material culture, reflecting the ethno-cultural interaction of the Udmurt people with the Turks - the Bulgars, the Kazan Tatars and the Bashkirs. Different ethnic and ethnographic groups of the Udmurt people find past sustainable conservatism in relation to such significant subject as a women's headwear on a birch bark base. A similar phenomenon was observed in the Komi, the Mari and the Mordvins. Close cooperation with the Turks led to the loss of the headwear on the birch bark base and its replacement with a cloth cap with an open top. In the tradition of a number of ethnographic subdivisions of Udmurtia, the shirt has retained the oldest tunic-like style with a right-shifted breast cut, also known among the Komi and the Meadow Mari. As a result of ethnocultural interaction with the Turks, in the traditions of the besermyan subethnos and some Udmurt ethnographic units there appeared a tunic-like shirt with a central breast section and a low breastplate kykrak. Turkic influence reflected an appearance of pants with a wide pitch in some Southern Udmurts and Besermyans, which replaced pants with a narrow pitch. The sets of traditional decorations from silver coins of the Besermyans and many ethnographic subdivisions of the Udmurts included a sash borrowed from various Turkic ethnoses, which was reflected in the names of this object. The process resulted in the formation of the Besermyan subethnos and was reflected in the appearance of traditional costume forms closely resembling the traditions of the Turkic peoples. Similar processes took place in various ethnographic and ethnic subdivisions of the Udmurt people. They are also reflected in the forms of traditional dress.

Keywords: Besermyans, Udmurts of Zakamie region, verhneizsk-sharkan Udmurts, Udmurt-Turkic cooperation, traditional costume.

\section{REFERENCES}

1. Ahmetyanov R. G. Kratkiy istoriko-etimologicheskiy slovar' tatarskogo iazyka [A Brief Historical and Etymological Dictionary of the Tatar Language]. Kazan, Tatar book Publ., 2001, 272 p. (In Russian).

2. Bagin S. Ob otpadenii v magometanstvo kreshchyonyh inorodtsev Kazanskoy eparhii i o prichinah etogo pechalnogo yavleniya [About the falling away of the baptized foreigners of the Kazan diocese into Mohammedanism and the reasons for this sad phenomenon]. Kazan, "Tsentralnaya tipografiya" Publ., 1910, 38 p. (In Russian).

3. Belitser $V$. Narodnaia odezhda udmurtov (materialy $\mathrm{k}$ etnogenezu) [Folk clothes of the Udmurts (materials for ethnogenesis)]. Trudy instituta etnografii. Novaya seriya [Proceedings of the Institute of Ethnography. New series]. Vol. 10. Moscow, Ed. of the USSR Academy of Sciences, 1951, 142 p. (In Russian).

4. Belitser $V$. Ocherki po etnografii komi [Essays on the ethnography of the Komi]. Trudy instituta etnografii. Novaya seriya [Proceedings of the Institute of Ethnography. New series]. Vol. 45. Moscow, Ed. of the USSR Academy of Sciences, 1958, 322 p. (In Russian).

5. Bobrovnikov N. A. Inorodcheskoe nasilenie Kazanskoy gubernii [Non-Russian population of Kazan province]. Issue I. Kazan, [n. a.], 1899. 68 p. (In Russian).

6. Valeev F. H. Narodnoe dekoranbvnoe iskusstvo Tatarstana [Folk decorative art of Tatarstan]. Kazan, Tatar book Publ., 1984, 172 p. (In Russian).

7. Vereshchagin G. E. Votyaki Sosnovskogo kraya. Sobr. Soch. v 6 tomah. Tom 6 [Votyaki of the Sosnovsky Territory. Collected Works in 6 volumes. Vol. I]. Izhevsk, Ed. of the Udmurt Institute of History, Language and Literature of the Ural Branch of the Russian Academy of Sciences, 1995, 215 p. (In Russian).

8. Gagen-Torn N. I. Zhenskaya odezhda narodov Povolzhya. (Materialy k etnogenezu) [Women's clothing of the peoples of the Volga region. (Materials for ethnogenesis)]. Cheboksary, Chuvash book Publ., 1960, 228 p. (In Russian).

9. Grosheva A. N., Shneyder Y. V., Morozova I. Y., Zhukova O. V., Rychkov S. Y. Genenticheskoe raznoobrazie besermian po dannym o polimorfizme mitohondrialnoy DNK [Genetic diversity of besermyans according to data on mitochondrial DNA polymorphism]. Genetika [Genetics], 2013, no. 3, pp. 1337-1344. (In Russian).

10. Kelmakov V. K. K istorii udmurtov Pravoberezh'ia r. Vyatki [To the history of the Udmurts on the right bank of the Vyatka river]. Materialy po etnogenezu udmdrtov [Materials on the ethnogenesis of the Udmurts]. Izhevsk, Ed. of the Research Institute at the SM of the Udmurt Autonomous Soviet Socialist Republic, 1982, pp. 138-142. (In Russian).

11. Kozlova K. I. Ocherki etnicheskoy istorii mariyskogo naroda [Essays on the ethnic history of the Mari people]. Moscow, Moscow State University Press, 1978, 345 p. (In Russian).

12. Kosareva I. A. Traditsionnaia zhenskaia odezda periferiynyh grupp udmurtov [Traditional women's clothing of the peripheral groups of the Udmurts]. Izhevsk, Ed. of the Udmurt Institute of History, Language and Literature of the Ural Branch of the Russian Academy of Sciences, 2000, 226 p. (In Russian).

13. Kosareva I. A. Kalmez - etnograficheskaya gruppa udmurtov. (Osobennosti traditsionnoy kultury i lokalizatsiya) [Kalmez is an ethnographic group of Udmurts. (Features of traditional culture and localization)]. Vestnik 
udmurtskogo universiteta. Seriya Istoriya i filologiya [Bulletin of the Udmurt University. Series History and Philology], 2011, no. 3, pp. 135-141. (In Russian).

14. Kosareva I. A. Verhneizhsko-sharkanskaya etnograficheskaya gruppa udmurtov v svete problemy udmurtskotyurkskogo vzaimodeystviya [Verkhneizhsko-Sharkan ethnographic group of Udmurts in the light of the problem of Udmurt-Turkic interaction]. Vestnik udmurtskogo universiteta. Seriya Istoriya i filologiya [Bulletin of the Udmurt University. Series History and Philology], 2012, no. 1, pp. 91-96. (In Russian).

15. Kosareva I. A. Vodzimonyinskaya podgruppa sobstvenno-yuzhnyh udmurtov [Vodzimonian subgroup of the propersouthern Udmurts]. Vestnik Chelyabinskogo universiteta [Bulletin of the Chelyabinsk University], 2015, no. 65, pp. 17-21. (In Russian).

16. Kosareva I. A. Naboryi ukrasheniy etnograficheskih podrazdeleniy udmurtov. (Sravnitelniy analiz) [Sets of jewelry of ethnographic divisions of the Udmurts. (Comparative analysis)]. Vestnik udmurtskogo universiteta. Seriya Istoriya i filologiya [Bulletin of the Udmurt University. Series History and Philology], 2017, no. 1, pp. 83-87. (In Russian).

17. Kosareva I. A. Etnograficheskie gruppy udmurtskogo naroda (opyt vydeleniia) [Ethnographic groups of the Udmurt people (separation experience)]. IOAIE pri Kazanskom universitete [Proceedings of the Society of Archeology, History and Ethnography at Kazan University], 2017, vol. 37, no. 2, 195 p.; no. 3, 187 p. (In Russian).

18. Molotova T. L. Mariyskiy narodniy kostyum [Mari folk costume]. Ioshkar-Ola, Mari book Publ., 1992,109 p. (In Russian)

19. Napolskih $V$. V. Udmurtskie materialy Messershmidta [Udmurt materials of Messerschmidt]. Izhevsk, "Udmurtia" Publ., 2001, 222 p. (In Russian).

20. Pervuhin N. G. Eskizy predaniy i byta inorodtsev Glazovskogo uezda [Sketches of legends and life of foreigners of Glazovsky district]. Issue 5. Vyatka, [n. a.], 1890, 68 p. (In Russian).

21. Suslova $S$. $V$. Tatarskiy kostyum. Istoriko-etnologicheskoe issledovanie [Tatar costume. Historical and ethnological research]. Kazan, Tatar book Publ., 2018, 238 p. (In Russian).

22. Trofimova N. V., Litvinov S. S., Husainova R. I. Geneticheskaya harakteristika populyatsiy Volgo-Uralskogo regiona po dannym ob izmenchivosti Y-hromosomy [Genetic characteristics of the population of the Volga-Ural region according to the data on the variability of the Y-chromosome]. Genetika [Genetics], 2015, vol. 51, no. 1, pp. $120-127$. (In Russian).

23. Trefilov G. N. Besermyane po pismennym istochnikam [Besermyans according to written sources]. VFUY [FinnoUgric linguistics issues], 1967, issue IV, pp. 310-318. (In Russian).

24. Shitova S. N. Narodnaya odezhda bashkir [Bashkir folk clothes]. Arheologiya i etnografiya Bashkirii [Archeology and ethnography of Bashkiria], 1968, vol. 3, pp. 125-227. (In Russian).

Received 01.03.2020

Kosareva I. A., Candidate of History, Associate professor at department of Arts History Udmurt State University

Universitetskaya st., 1/6, Izhevsk, Russia, 426034

E-mail: kosar_irina@mail.ru 